\title{
Rancang Bangun Sistem Pendukung Keputusan Penilaian Karyawan Terbaik Pada PT. Surya Toto Indonesia, Tbk Menggunakan Metode Simple Additive Weighting (SAW) Berbasis WEB
}

\author{
Rohmat Taufiq ${ }^{1}$, Ahmad Hambali² ${ }^{2}$ Aries Saifudin ${ }^{3}$ \\ 1,2Teknik Informatika, University of Muhammadiyah Tangerang, Jalan Perintis Kemerdekaan I Babakan \\ No.33, RT.007/RW.003, Cikokol, Kec. Tangerang, Kota Tangerang, Banten 15118 \\ ${ }^{3}$ Teknik Informatika, Universitas Pamulang, Serpong, Tangerang Selatan, Banten, Indonesia, 15310 \\ e-mail: 1'rohmat.taufiq@umt.ac.id; ${ }^{2}$ ahmadhambali1997@gmail.com; ${ }^{3}$ aries.saifudin@unpam.ac.id; \\ Submitted Date: March 09 ${ }^{\text {th }}, 2021$ \\ Revised Date: June $13^{\text {th }}, 2021$
}

\begin{abstract}
PT. Surya Toto Indonesia is a large company in Banten Province. This company is located on Jl. MH. Thamrin km. 7, Tangerang Banten. Until now, the number of employees is around 1.200 employees. With a large number of employees, a proper performance appraisal decision support system is needed so that the work results of employees can be clearly and well defined. Until now, the process for performance appraisal is still using paper or also called manual which causes the process to take a bit longer and reports cannot be enjoyed in real time. From the existing problems, a web-based decision support system is needed which will be able to facilitate all parties related to the performance appraisal process. The method used begins with communication with the parties involved. Furthermore, planning, the process of data collection, analysis, planning, and finally reporting is carried out. The conclusion from this suggests that using the existing criteria provides two more criteria. By giving weights and calculations performed on three employees, the score obtained for employee $\mathrm{C}$ got the highest score $(0.92)$ followed by employee $\mathrm{B}$, and the lowest score (0.84) was employee A.
\end{abstract}

Keyword: Decision Support System, Best Employees, Simple Additive Weighting (SAW), System Design

\begin{abstract}
Abstrak
PT. Surya Toto Indonesia merupakan perusahaan besasr yang ada Propinsi Banten. Perusahaan ini bertempat di Jl. MH. Thamrin km. 7, Tangerang Banten. Samapai saat ini jumlah karyawan sekitar 1.200 pegawai. Dengan jumlah karyawan sebanyak maka dibutuhkan sebuah sistem pendukung keputusan penilaian kinerja yang tepat agar hasil kerja karyawan bisa terdefinisi dengan jelas dan baik. Sampai saat ini proses yang dilakukan untuk penilaian kinerja masih menggunakan kertas atau biasa juga disebut manual yang menyebabkan proses sedikit lama dan laporan belum bisa dinikmati secara real time. Dari permasalahan yang ada maka dibutuhkan sesbuah sistem pendukung keputusan berbasis web yang nantinya bisa memudahkan semua pihak yang berhubungan dengan proses penilaian kinerja.. Metode yang digunakan dimulai dengan komunikasi dengan pihak yang terlibat. Selanjutnya, perencanaa, proses pengumpulan data, analisis, perencanaan, dan akhirnya pembuatan laporan dilakukan. Kesimpulan dari ini memberikan saran untuk menggunakan kriteria yang telah ada memberikan dua kriteria lagi. Dengan memberi bobot dan perhitungan yang dilakukan terhadap tiga orang karyawan, nilai yang diperoleh untuk karyawan $\mathrm{C}$ mendapat skor tertinggi (0.92) diikuti oleh karyawan $\mathrm{B}$, dan nilai terendah (0.84) adalah karyawan A.
\end{abstract}

Kata Kunci: Sistem Pendukung Keputusan, Karyawan Terbaik, Simple Additive Weighting (SAW), Rancang Bangun 


\section{Pendahuluan}

Penentuan karyawan terbaik serta berkualitas adalah salah satu asset pada dunia industri yang nantinya akan menjadikan dunia perindustrian berkembang sangat maju. membangun perusahaan berkembang sangat pesat. Oleh karena itu semangat kerja pegawai memiliki pengaruh kuat bagi hasil kerja serta sangat menguntungkan bagi perusahaan. Maka dari itu industri membutuhkan pegawai yang memiliki kemampuan yang tinggi bagi perusahaan. Agar kinerja dan hasil kerja karyawan maksimal maka industri membutuhkan usaha yang maksimal.

Agar perusahaan mendapatkan hasil kerja yang maksimal dari pegawainya salah satu caranya yaitu menentukan pegawai terbaik untuk mendorong pegawainya agar termotivasi untuk memberikan hasil kerja yang maksimal. Dengan meningkatnya hasil kerja pada industri yang dinilai kinerja karyawannya maka keuntungan perusahaan juga akan meningkat.

Sebuah proses pengambilan keputusan dibutuhkan kecepatan dan akurasi yang tinggi, karena dengan kecepatan pengambilan keputusan akan lebih cepat juga proses percepatan yang ingin dicapai perusahaan. Untuk mengambil keputusan dengan cepat dan tepat dibutuhkan sebuah metode yang memang sudah sering digunakan seperti ahp, saw, topis dan atua metode yang lainnya.

Evaluasi pegawai karyawan terbaik di PT Surya TOTO Indonesia memikiki 15 kriteria dalam proses penilaiannya. Adapun penilaian tersebut hanya diambil dari nilai rata-rata semua nilai. Penentuan karyawan terbaik menggunakan multiple kriteria akan memberikan hasil yang terbaik apalagi jika kriteria tersebut diberikan bobot pada masing-masingnya. Bobot yang di berikan pada kriteria tersebut nantinya akan membuat pengambilan keputusan penentuan karyawan terbaik menjadi lebih profesional.

Mengacu dari latar belakang di atas maka peneliti akan merancang serta membangun sebuah sistem pengambilan keputusan pegawai terbaik di PT Surya TOTO Indonesia menggunakan metode Simple Additive Weighting (SAW). Metode ini digunakan karena dinilai paling tepat untuk menghitung proses sistem pendukung keputusan penilaian kinerja pegawai di dunia industri khususnya di PT. Surya TOTO yang memiliki jumlah karyawan kurang lebih 1.200 oang. Selain itu metode ini belum pernah digunakan untuk evaluasi kinerja pagawai di perusahaan tersebut. Dan akhirnya hasil diskusi peneliti dengan pihak manajemen perusahaan menyepakati metode ini.

\section{Tinjauan Pustaka \\ Perancangan Sistem}

Penggambaran rinci sistem yang akan berjalan yang terdiri dari kumpulan kegiatankegiatan secara berurutan merupakan langkah dari pengembangan sistem (Satzinger, Jakson dan Burd, 2012). Sedangkan menurut (Subhan, 2012) pengembangan sistem merupakan suatu kegiatan yang menghasilkan spesifikasi baru hasil dari analisis. Menurut Munawar dalam Syepry dkk menjelaskan pengembangan sistem merupakan bagaimana proses pengembangan sistem walaupun kenyataannya tidak benar-benar terwujud (Syepry dkk, 2020). Kegiatan analisis dilakukan terlebih dahulu agar memberikan kemudahan sebelum proses perancangan sistem dilakukan (Pertiwi dan Taufiq, 2020). Hasil dari analisis selanjutnya dilakukan perancangan berbasis web (Taufiq dkk, 2020).

Langkah-langkah dalam pengembangan sistem merupakan kegiatan yang dilakukan secara rinci dan teratur mengacu hasil dari analisis sistem yang dilakukan sehingga dapat memberikan hasil sebuah model baru yang dihasilkan (Mahdiana, 2011). Sedangkan tujuan perancangan adalah terpenuhinya kebutuhan para pemakai atau user, yang mampu memberikan penjelasan agar bisa diimplementasikan dengan baik (Darmawan, 2013).

\section{Sistem Informasi}

Ada beberapa definisi sistem yang bisa dijadikan sebagai referensi diantaranya sistem merupakan hubungan tata cara yang sudah di sepakati sesuai dengan pola yang ditentukan guna mendukung pelaksanaan kegiatan-kegiatan pokok industri. Sedangkan prosedur merupakan runtutan aktifitas yang melibatkan banyak orang dalam satu bagian agar terjamin penanganan transaksi yang seragam di perusahaan (Mulyadi, 2014). Sedangkan pengertian Sistem informasi adalah kumpulan dari sub-sub sistem yang saling berhubungan dan bekerjasama guna mendukung penyelesaian masalah-masalah khusus dengan cara mengelola data sehingga mendapatkan nilai tambah serta memiliki manfaat bagi pengguna sistem itu sendiri (Taufiq, 2018).

\section{Sistem Pendukung Keputusan}

Sistem Pendukung Keputusan (SPK) adalah berkumpulnya komponen-komponen yang saling 
berhugungan dan bekerjasama guna memberikan solusi dari masalah yang ada didalamnya dengan cara mencari bebagai alternative yang memiliki hubungan erat dengan permasalahan (Taufiq, 2018). Sedangkan menurut Man dan Watson (2012) didalam jurnal Fitri dan Nurhadi (2017) SPK adalah sebuah sistem yang sangat interaktif guna mendukung proses pengambilan keputusan dengan cara penggunaan data-data dan modelmodel keputusan agar masalah yang dihadai bisa diselesaikan.

\section{Penilaian Kinerja}

Beberapa definisi penilaian kinerja di antaranya menurut (Dessler, 2015) memberikan penjelasan bahwa evaluasi kinerja pegawai merupakan proses menilai hasil kerja pegawi dari masa lalu hingga masa saat ini yang dibandingkan dengan standar yang sudah ada. Sedangkan dari ahli yang lain menjelaskan bahwa standar operasional prosedur yang diakui itu dilaksanakan dalam sebuah organisasi guna melakukan evaluasi karyawan yang ada (Hasibuan, 2012). Evaluasi kinerja pegawai merupakan kegiatan penilaian prestasi yang dilakukan pimpinan suatu perusahaan secara sistematika berdasarkan pekerjaan yang ditugaskan kepadanya (Mangkunegara, 2011).

\section{Metode Pengembangan}

Bagian ini dapat meliputi analisa, arsitektur, metode yang dipakai untuk menyelesaikan masalah, implementasi. Metode penelitian ini memiliki tujuh langkah yang terdiri dari pengumpulan kebutuhan, membangun prototyping, evaluasi prototyping, mengkodekan sistem, menguji sistem, evaluasi sistem, penggunaan sistem.

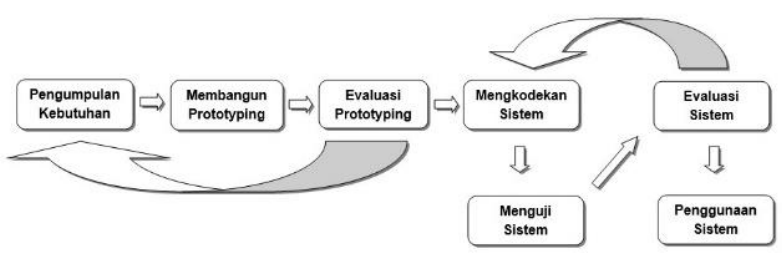

Gambar 1. Metode Penelitian

Dalam langkah metode pengembangan yang tertera dalam Gambar 1 di atas terdapat 7 langkah. Langkah awal dimulai dari pengumpulan kebutuhan yang dilanjutkan sampai membangun prototype sampai langkah akhir penggunaan sistem. Sebelum dilakukan penggunaan sistem dilakukan pengujian terlebih dulu. Pengujian aplikasi memiliki peranan penting dalam suatu pengembangan sistem karena bertujuan untuk menemukan Galat atau Error yang akan muncul pada sistem dan memperbaiki (Ahrizal, Miftah, Kurniawan, Zaelani, \& Yulianti, 2020). Pengujian sistem bertujuan untuk memastikan bahwa semua proses sudah berfungsi sesuai dengan kebutuhan yang ditetapkan (Muslimin, et al., 2020).

\section{Analisis dan Perancangan 4.1 Sistem yang Berjalan}

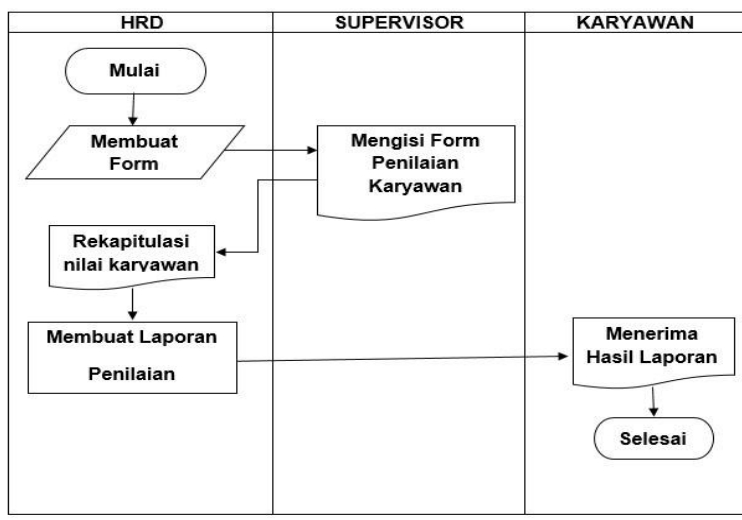

Gambar 2. Sistem yang berjalan

Proses-proses pada prosedur yang sedang berjalan dimulai dari HRD memberikan form penilaian ke supervisor, Supervisor mengisi bobot nilai pada form penilaian karyawan, penilaian diambil dari nilai rata-rata setiap kriteria selama 1 (satu) tahun. Setelah selesai, supervisor mengembalikan form penilaian ke HRD, HRD merekapitulasi form penilaian karyawan terbaik, HRD memproses penilaian karyawan terbaik dan langkah terakhir yaitu HRD membuat laporan penilaian dan menentukan karyawan yang terbaik.

\subsection{Melakukan Perhitungan dengan Metode SAW}

Dalam perhitungan dengan menggunakan metode SAW ini ada 8 langkah yang digunakan mulai dari menentukan jenis kriteria sampai hasil akhir nilai preferensi. Terdapat 15 jumlah kriteria yang digunakan terdiri dari kuantitas, kualitas, delivery, pelaksanaan SOP, penguasaan kerja, minim kesalahan, kerja sama, moral dan perilaku, keuletan, inisiatif, absensi, waktu, peringatan, 5S dan K3 serta Inovasi.

Tabel 1. Rating keputusan

\begin{tabular}{|c|c|}
\hline A3 = Karyawan C & 0,92 \\
\hline A2 $=$ Karyawan B & 0,91 \\
\hline A1 $=$ Karyawan A & 0,84 \\
\hline
\end{tabular}


Nilai terbesar ada pada V3, dengan demikian alternatif A3 yang terpilih sebagai alternatif terbaik.

\subsection{Perancangan Sistem}

\section{Use Case}

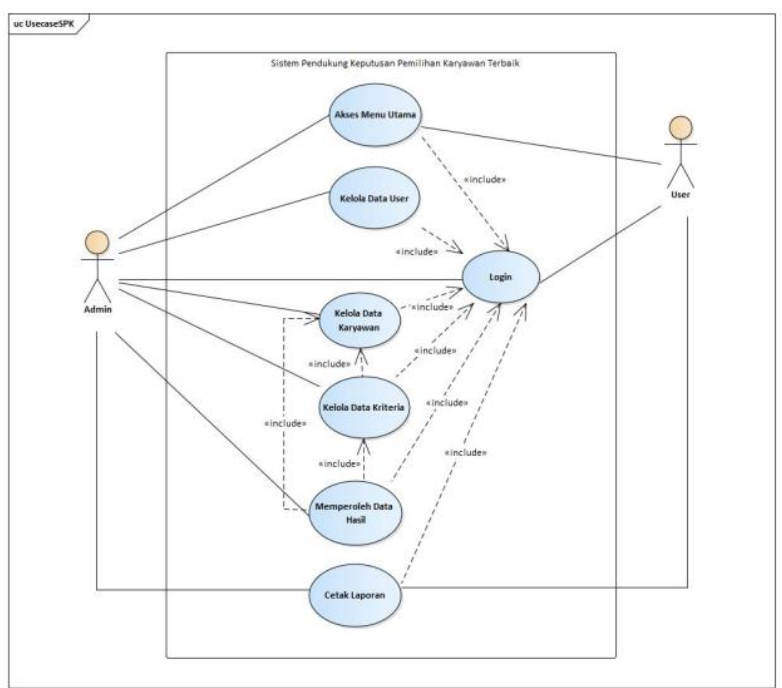

Gambar 3. Use case diagram spk

Dalam Gambar 3 use case di atas menjelaskan bagaimana dua aktor berhubungan dengan sistem. Aktor pertama admin dan aktor yang kedua adalah Aktor yang mempunyai hak akses untuk melakukan melihat hasil dan mencetak laporan penilaian karyawan terbaik. Masingmasing aktor memiliki user name dan password dan hak akse yang berbeda-beda.

\section{Statechart}

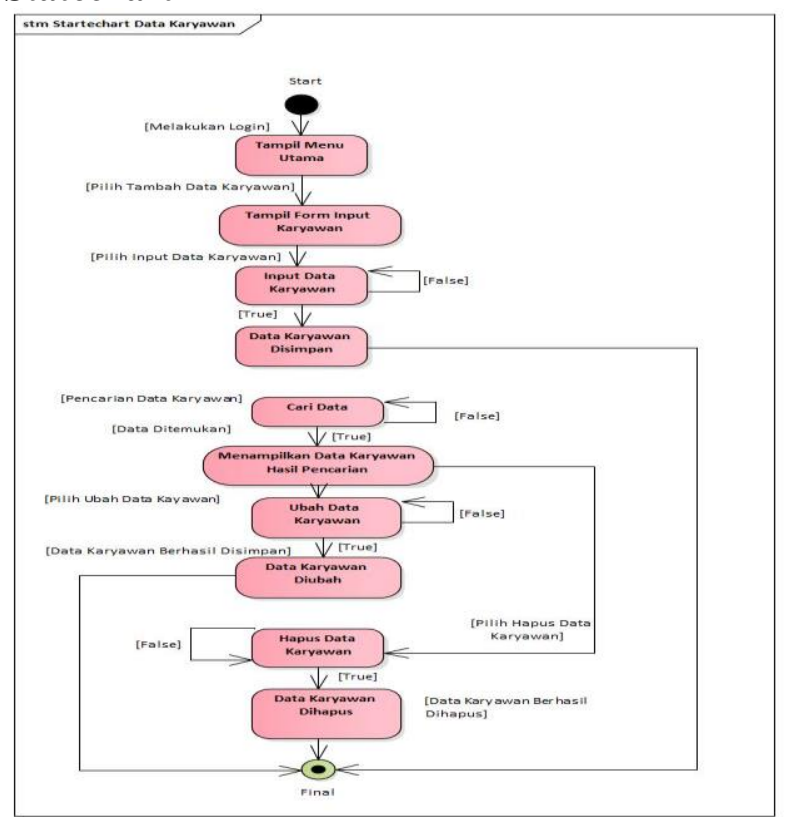

Gambar 4 Statechart diagram kelola data karyawan
Statechart diagram menggambarkan state machine. Ini memiliki arti bahwa bagaima mesin atau komputer melakukan sesuai dengan apa user lakukan. Statechart diagram kelola data karyawan yang ditampilkan dalam paper ini, namun sebenarnya terdapat statechart login, kelola data user, kelola data kriteria, data hasil dan cetak laporan.

\section{Activity}

Ada beberapa activity yang dilakukan dalam penelitian ini namun dalam paper ini hanya ditampilkan activity kelola data karyawan. Activity data karyawan ditampilkan dalam gambar 5 di bawah ini.

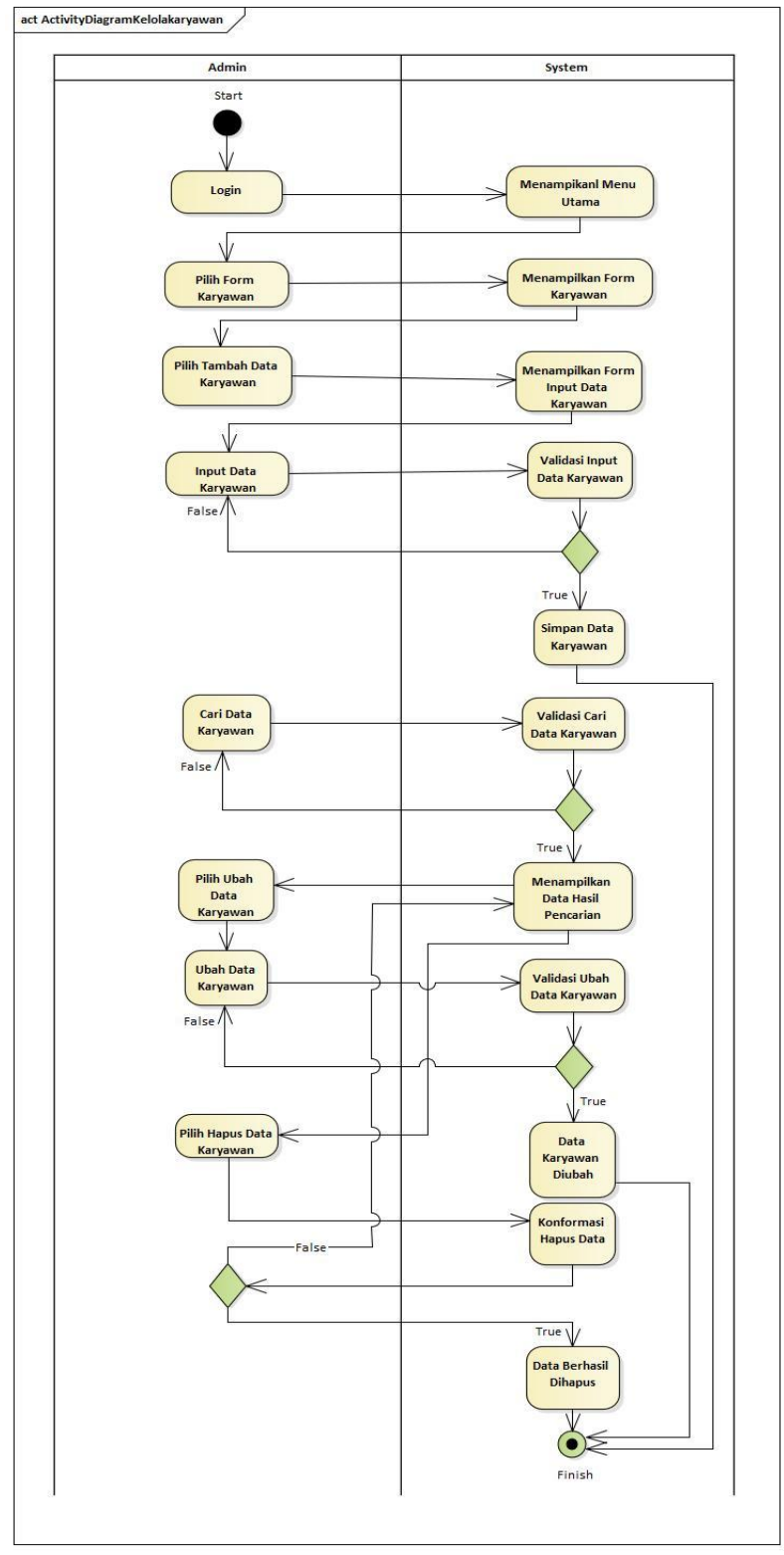

Gambar 5 Activity diagram kelola data karyawan 
Activity diagram kelola data karyawan yang dijelaskan dalam Gambar 5 di atas berkenaan tentang admin dengan sistem. Langkah awal admin melakukan login lalu sistem menampilkan menu utama sampai dengan data berhasil disimpan. Activity ini memiliki kemampuan bagaimana seorang admin mengelola data karyawan didalamnya bisa digunakan untuk menyimpan, mengubah dan menghapus data karyawan.

\section{Sequence}

Gambar 6 di bawah ini merupakan sequence diagram yang digunakan untuk kelola data karyawan.

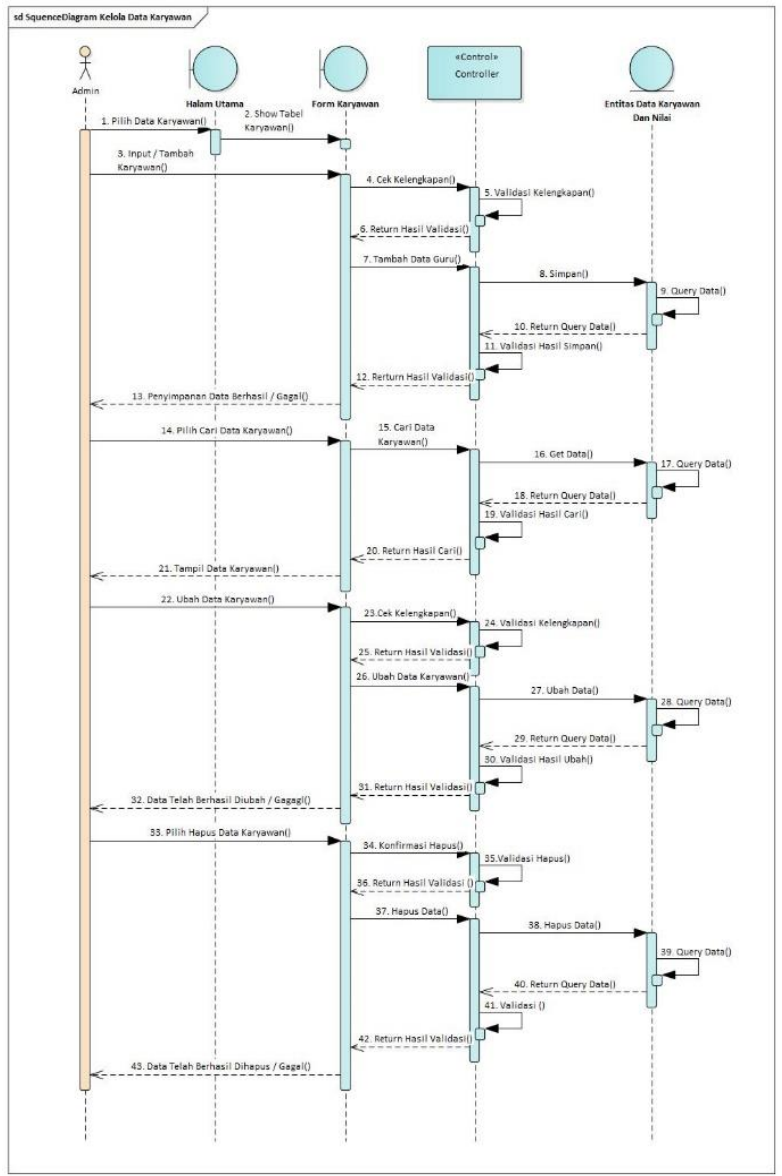

Gambar 6 Sequence kelola data karyawan

Sequence kelola data karyawan yang tertera pada gambar 6 di atas menjelaskan bagaimana seorang aktor yang namanaya Admin berhubungan dengan sistem yang dibangun. Langkah awal admin memilih data karyawan melalu halaman utama yang selanjutnya masuk ke form karyawan lalu controller dan yang terakhir masuk ke database. Database memberikan informasi ke admin sesuai dengan apa yang dibutuhkan.

\section{Desain Antarmuka}

Setelah melakukan desain logic mengunakan UML, langkah berikut adalah desain fisik. Dalam desain fisik terdapat 23 desain yang nantinya akan dikembangkan dalam aplikasi SPK Penilaian Karyawan Terbaik di PT. Surya TOTO

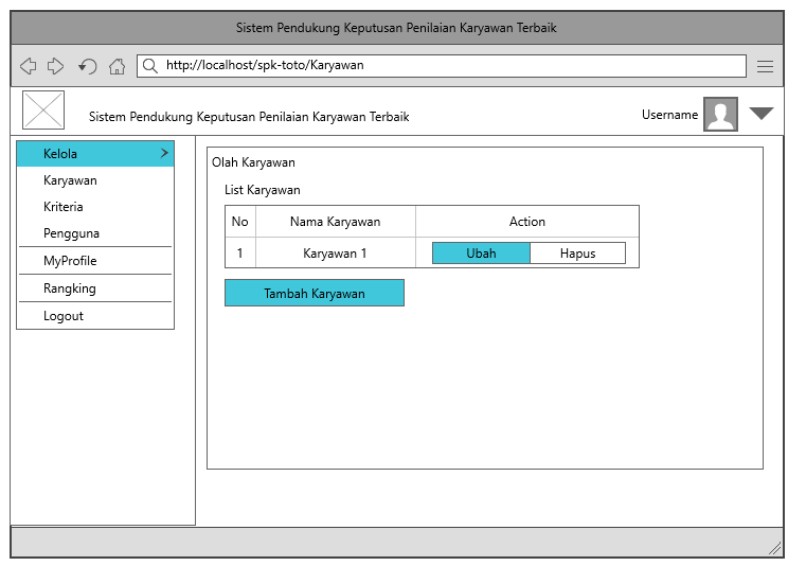

Gambar 7 Desain kelola data karyawan

Desain kelola data karyawan seperti yang tertera pada gambar 7 di atas menggambarkan bahwa aplikasi yang akan dibangun nanti akan mampu digunakan untuk menambah, mengubah dan menghapus data karyawan.

\subsection{Implementasi Form menu Login}

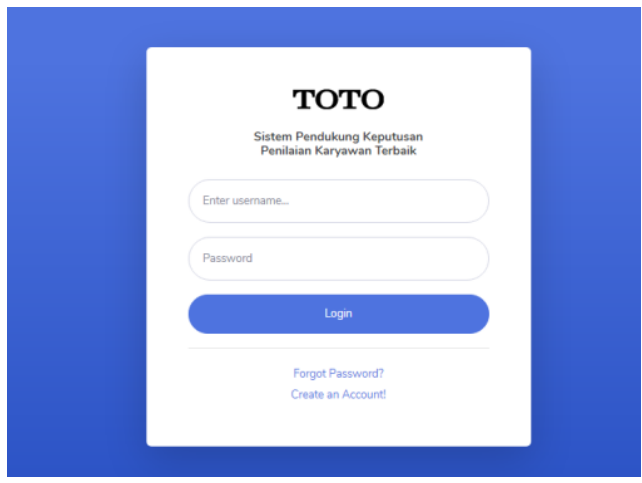

Gambar 8. Form menu login

Gambar 8 merupakan form utama sebelum masuk ke aplikasi selanjutnya. Di sini akan dilakukan verifikasi data pengguna yang akan masuk. Jika sesuai dengan data base maka pengguna berhak login namun jika tidak maka pengguna tidak bisa login. Selain itu ada juga menu untuk membuat password baru jika lupa dengan passwordnya dan create account bagi yang belum memiliki akun. 


\section{Form Selamat Datang Admin}

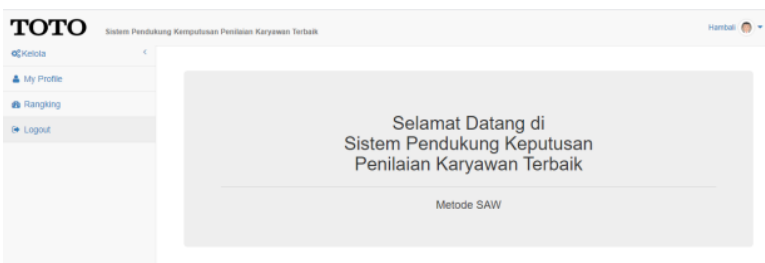

Gambar 9 Form selamat datang admin

Setelah login berhasil masuk akan muncul menu selamat datang. Sebenarnya dalam aplikasi ini terdapat kurang lebih 23 form yang sudah dibuat. Namun tidak bisa ditampilkan semuanya dan ditampilkan yang pentung saja dalam paper ini.

\section{Form kelola data karyawan}

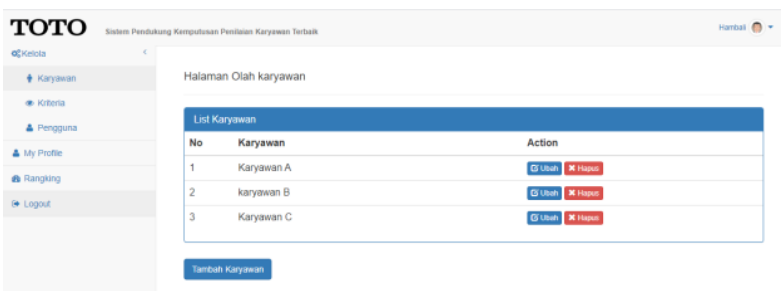

Gambar 10 Form kelola data karyawan

Gambar 10 di atas sesuai dengan desain yang terdapat pada gambar 7 kelola data karyawan. Sebagai contoh penggunaan metode SAW ini jumlah karyawan yang diinput dan di hitung 3 orang. Karyawan A, B dan C. Tiga karyawan itulah yang nantinya akan dihitung.

\section{Form Kelola Kriteria}

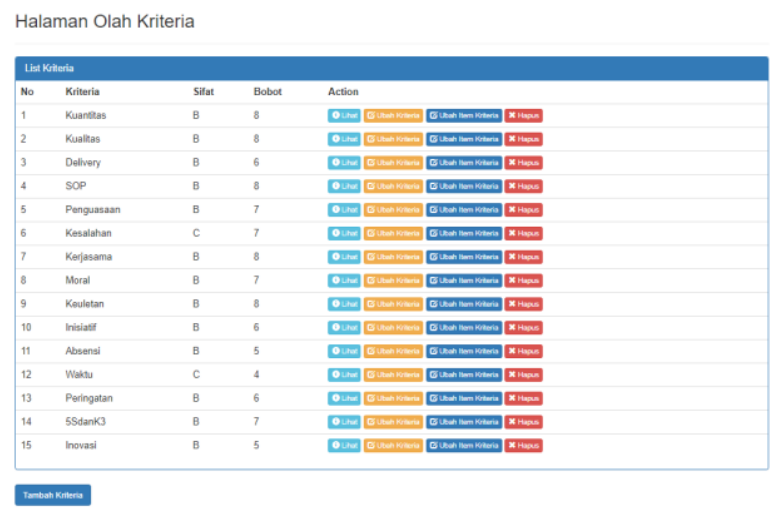

Gambar 10 Form kelola kriteria
Kelola kriteria yang terdapat pada gambar 10 berfungsi untuk menginput, mengubah kriteria, merubah item kriteria dan menghapus. Terdapat 15 kriteria yang digunakan untuk menilaia karyawan yang dimulai dari kuantitas sebagai kriteia pertama sampai kriteria inovasi sebagai kriteria yang ke 15 .

\section{Form lihat detail kriteria}

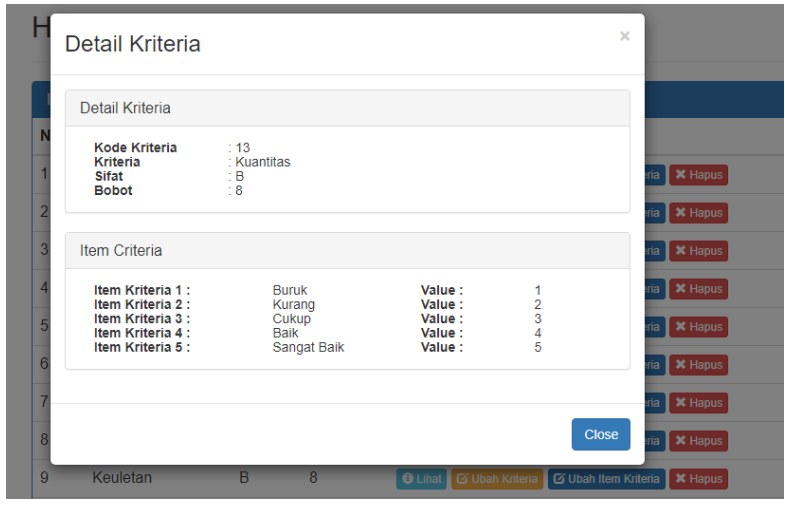

Gambar 11 Form lihat detail kriteria

Gambar 11 menampilkan sebuah form aplikasi dari SPK penilaian kinerja karyawan dengan menggunakan metode SAW. Form lihat detail kriteria bisa digunakan untuk melihat secara detail semua kriteria yang digunakan. Sebagai contoh dalam gambar 10 untuk melihat detail kriteria dengan kode 13 (kriteria kuantitas). Kriteria kuantitas diberikan bobot 8 sesuai dengan keadaan di lapangan.

\section{Form perhitungan SAW dengan Aplikasi}

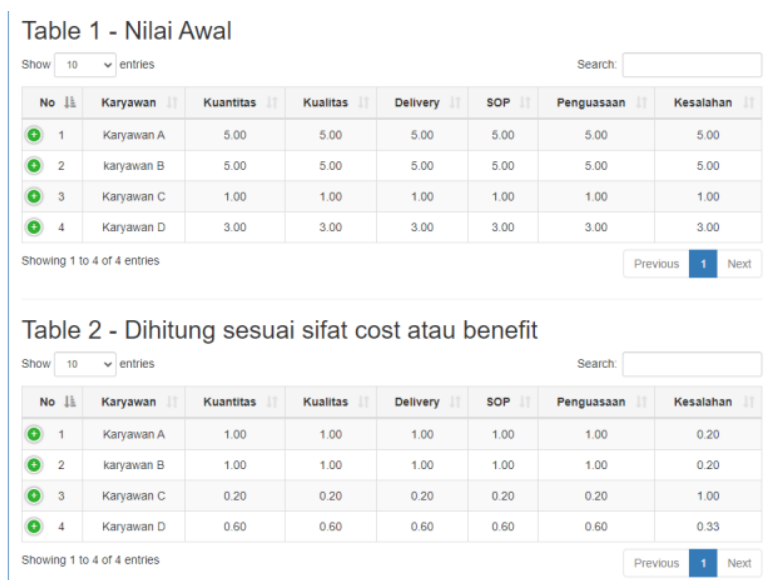

Gambar 12 Form kelola kriteria

Perhitungan SAW dengan aplikasi pada kenyataannya terdapat 4 tabel namun dalam paper 
ini yang di masukkan adalah tabel 1 dan 2. Tabel 1 merupakan nilai awal yang dimasukkan oleh admin sedangkan tabel 2 untuk menghitung cost atau benefit yang dimiliki oleh masing-masing kriteria. Perhitungan yang tertera dalam aplikasi ini tingkat kebenarannya sudah disesuaikan dengan perhitungan manual yang dilakukan sebelumnya.

\section{Form Cetak Rangking}

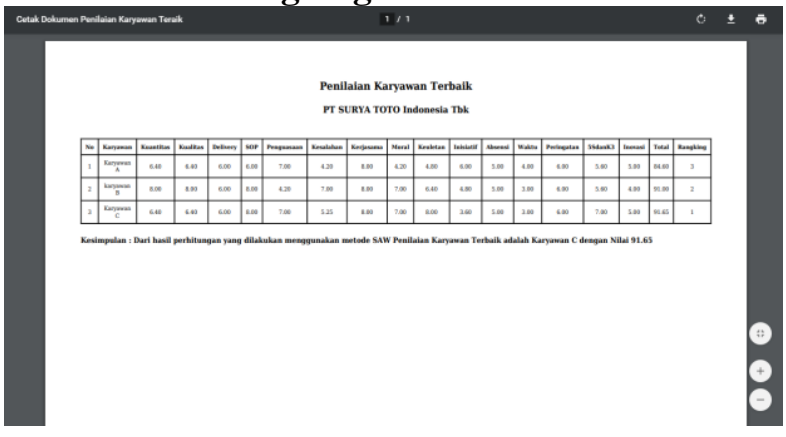

Gambar 13 Form cetak rangking

Gambar 13 menjelaskan pengurutan atau pemeringkatan dari 3 karyawan dengan menggunakan 15 kriteria yang dihitung dengan metode SAW. Hasil akhir dari uji coba SPK penilaian kinerja didapatkan karyawan $C$ peringkat 1 dilanjutkan karyawan $\mathrm{B}$ dan yang terakhir adalah karyawan A.

\section{Kesimpulan}

Bobot nilai perhitungan adalah merupakan salah satu indikator penting dalam perhitungan pengambil keputusan menentukan penilaian karyawan terbaik. Hasil dari pembahasan yang dijelaskan di atas, sebuah pengembangan sistem pengambilan keputusan dapat membantu menentukan atau menyelesaikan suatu masalah dalam memberikan rekomendasi karyawan terbaik pada PT. SURYA TOTO Indonesia Tbk. Sistem pendukung keputusan yang diusulkan mudah digunakan oleh admin dan user. design user interface yang menarik, dan mudah dipahami.

\section{Referensi}

Ahrizal, D., Miftah, M. K., Kurniawan, R., Zaelani, T., \& Yulianti, Y. (2020). Pengujian Perangkat Lunak Sistem Informasi Peminjaman PlayStation dengan Teknik Boundary Value Analysis Menggunakan Metode Black Box Testing. Jurnal Informatika Universitas Pamulang, 5(1), 7377. doi:10.32493/informatika.v5i1.4338
Darmawan. 2013. Metode Penelitian Kuantitatif. Bandung: Remaja Rosdakarya.

Dessler, Gary (2015). Manajemen Sumber Daya Manusia. Jakarta. Salember Empat.

Fitri NY dan Nurhadi (2017). Analisa dan Perancangan Sistem Pendukung Keputusan Penilian Kinerja Guru Degan Metode Simple Additive Weighting (SAW) Pada SMK Yadika, Jurnal Manajemen Sistem Informasi, Vol.2, No.1, Maret 2017.

Hasibuan, Malayu SP. (2012). Manajemen SDM. Edisi Revisi, Cetakan ke Tigabelas. Jakarta: Bumi Aksara.

Husain, SM. Azhari, L. Taufiq, R dan Rahma, A (2020). Rancang Bangun Aplikasi E-Library Fakultas Teknik Universitas Muhammadiyah Tangerang. Jurnal Informatika UMT. E ISSN: 2722-2713. November 2020. Pp. 64-72.

Mahdiana, D (2011). Analisa dan Rancangan Sistem Informasi Pengadaan Barang Dengan metodologi Berorientasi Objek: Studi Kasus PT. Liga Indonesia. Jurnal Telematika mkom, Vol. 3 No. 2. September 2011.

Mangkunegara (2011). Manajemen Sumber Daya Perusahaan. PT. Remaja Rosdakarya. Bandung.

Mulyadi (201). Sistem Informasi Akuntansi. Salemba Empat. Jakarta.

Muslimin, D. B., Kusmanto, D., Amilia, K. F., Ariffin, M. S., Mardiana, S., \& Yulianti, Y. (2020). Pengujian Black Box pada Aplikasi Sistem Informasi Akademik Menggunakan Teknik Equivalence Partitioning. Jurnal Informatika Universitas Pamulang, 5(1), 19-25. doi:10.32493/informatika.v5i1.3778

Pertiwi, D.D and Taufiq, R. 2020. "Analisis dan Desain Sistem Informasi Pengolahan Nilai Siswa di SMK Avicena Rajeg”, J. Tek. Inform. Univ. Muhammadiyah Tangerang. ISSN: 2549-0710.

Satzinger, JW., Jackson, RB dan Burd, SD (2012). Systems Analysis and Design in a Changing World. Cengage Learning. USA.

Subhan, M (2012). Analisa Perancangan Sistem. Jakarta. Lentera Ilmu Cendikia.

Taufiq, R. (2018). Pengantar Sistem Informasi”. Jakarta. Mitra Wacana Media.

Taufiq, R. (2018). Sistem Pendukung Keputusan. Jakarta. Mitra wacana Media.

Taufiq, R. Muttaqijn, MI. Mukhofa, MI dan Effendi, Y (2020). Sistem Informasi Manajemen. Edisi 2. Graha Ilmu. Yogyakarta.

Taufiq, R dan Sugiharto, A (2011). The Decision Support System Design of Employee Performance Apraisal using Analytical Hierarchy Process (AHP) Method. Proceedings of The $1^{\text {st }}$ International Conference on Information Systems For Business Competitiveness (ICISBC). 